\title{
INHALATION APPARATUS FOR GENERATING SARIN AND SOMAN TOXIC VAPORS
}

\begin{abstract}
Lucie Ševelová, Josef Vachek, Jiř́ Bajgar
Purkyně Military Medical Academy, Hradec Králové: Department of Toxicology

Summary: The developed inhalation system is a dynamic and whole-body exposure model designated for generating sarin or soman vapors. It consists of an evaporating apparatus, an inhalation chamber and a carbon filter. The inhalation chamber is made of stainless steel and its total volume is 361 . The concentration of organophosphorus compound depends on airflow through the chamber, syringe volume of the dosing pump and dosing speed. For determination of organophosphorus compound (OPC) concentration, a modification of Ellman method is used. At generating of vapors in the inhalation chamber the means of the yield were $61.4 \pm 6.6 \%$ for sarin and $35.8 \pm 3.5 \%$ for soman. The better yield for sarin than for soman, because of the higher volatility of sarin in comparison with soman was achieved. The stable concentration of the OPC for several hours could be maintained in the inhalation chamber when only relatively small amount of the OPC is used. Using the developed inhalation system $\mathrm{LCt}_{50}$ for sarin and for soman in rats was determined. At $1 \mathrm{~h}$ exposure the $\mathrm{LCt}_{50}$ values were $4.72 \mathrm{mg} \cdot \mathrm{h}^{-1} \cdot \mathrm{m}^{-3}$ for sarin and $4.81 \mathrm{mg} \cdot \mathrm{h}^{-1} \cdot \mathrm{m}^{-3}$ for soman. The results presented show that the inhalation chamber successfully fulfils the role of instrument for inhalation intoxication of small laboratory animals with highly toxic OPC.
\end{abstract}

Key words: Sarin; Soman; Inhalation apparatus; Rats; Whole-body exposure; Yield

\section{Introduction}

Organophosphorus compounds (OPC) including pesticides are potent cholinergics that annually affect approximately 3 million people worldwide and result in 220,000 deaths (WHO, 1996) (9). Recent events have illustrated the threat of the use of nerve agents in chemical warfare, in suppression of internal conflicts, and in terroristic attacks. Moreover, the presence of large stocks of these agents in various countries and the need to destroy these stockpiles raises the possibility of accidental exposure. Therefore, further studies on the toxicology of such agents are highly relevant (11). The respiratory tract and the skin are the main routes of entry of nerve agent to the body. The skin offers some protection by stratum corneum, but the respiratory tree is permeable to most toxic vapors (1). At most experiments with nerve agents realized on laboratory animals, the OPC are administered parenterally. This route of administration is not ideal, because it does not mimic the course of the most presumable way of intoxication good enough. During inhalation intoxication, the dose of OPC is distributed longer time and in smaller amounts than in case of parenteral application of the same total dose of OPC.

Basically, two types of inhalation systems are at hand: static systems (a) where the toxic agent is introduced to the inalation chamber as a batch before mixing and dynamic systems (b) where the introduction and removal of the agent are continuous due to a constant airflow through the inhalation chamber (15). The duration of static exposure is limited by the accumulation of carbon dioxide and water vapor, the gradual increase in temperature, and the gradual depletion of oxygen inside the chamber. In a dynamic system, these problems are avoided. Dynamic systems have therefore a broader range of applicabilities than static systems (1).

Dynamic inhalation chambers should be constructed as nose-only chambers or whole-body exposure chambers (5). Inhalation systems have to be constructed with respect to the animal species for which are designed. Mainly in nose - only exposure systems there are substantial differences in shape of breathing part. Special inhalation systems for mice (8), rats (6), guinea pigs (3) or baboons (2) have been already constructed and tested. For smaller rodent species, homogenous in size and growth, small head/nose-only chambers are commonly used up to subchronic exposure durations, whereas larger whole-body exposure chambers are used for long-term exposures or exposure paradigms exceeding the normal working day. It is often believed best that whole-body inhalation chambers simulate potential human exposure to environmental chemicals or pesticides 
and this serves as a justification for preferring this mode of exposure. Nose-only modes of exposure in inhalation studies are designed to reduce dosing from non-respiratory routes, except for large animal number, chronic inhalation studies or study types that require virtual continuous exposure (14). Additionally, it allows testing of high concentrations without the need for large quantities of test material. Also, instability of the test compounds (e.g. reactivity with excreta or humidity) and the possible heterogeneity of the test atmosphere in inhalation chambers is of least concern when head/nose-only inhalation chambers are used. The duration required to attain the inhalation chamber equilibration is minimal in head/nose-only chambers. However, this mode of exposure requires restraining of the animal (13).

Generation of controlled test atmospheres of toxic gases and vapors can be performed by using several different techniques. When the toxic gas under study is a liquid at room temperature, a vaporization step has to be included for generation of the gas. Different methods for vaporization may be used, which include solvent injection, evaporation, and electrolytic methods, permeation tubes and diffusion tubes (1).

The continuous monitoring of a test atmosphere is an integral measurement of all dynamic parameters of the system and hence provides an indirect, however, integrative means to controll all relevant, dynamic inhalation parameters. „Nominal concentrations“ reflect the mass of test substance introduced into the inhalation system relative to the total volume of air available for dispersion. Many factorsincluding wall loss, losses on the skin and fur of animals, for the whole-body mode of exposure, sedimentation and impaction especially of larger particulates, chemical reactivity - cause the „analytical“ or „,actual“ concentration to be substantially less than the nominal concentration. Therefore, the concentration present in the vicinity of the breathing zone should always be measured in an appropriate manner rather than reporting the nominal concentration alone (14). Frequency of determination of the analytical concentration should be at least 3-times during the exposure period (13). The inhalation chamber temperature as well as humidity have to be monitored during exposure.

This paper presents an inhalation system for experiments with highly toxic vapors such as sarin or soman. The whole-body exposure chamber for inhalation intoxication of small laboratory animals (mouse, rat, guinea-pig) with soman or sarin was developed at our institute. The aim of this study was to determine the relationship between the nominal and the analytical concentration of toxic vapors in the inhalation chamber.

\section{Material and methods}

\section{Inhalation apparatus}

The inhalation system consists of an evaporating apparatus, the inhalation chamber and a carbon filter (Fig. 1). All the inhalation system is maintained in negative pressure becuase of preventing leakage of the OPC into the surrounding areas. In addition, the instrument is kept in a hood to eliminate any risk of intoxication of the personnel operating the instrument. The air is sucked through the chamber by a sucking pump. The airflow through the system can be adjusted by flow meter located behind the inhalation chamber and ranges from 900 to $18001 . \mathrm{h}^{-1}$.

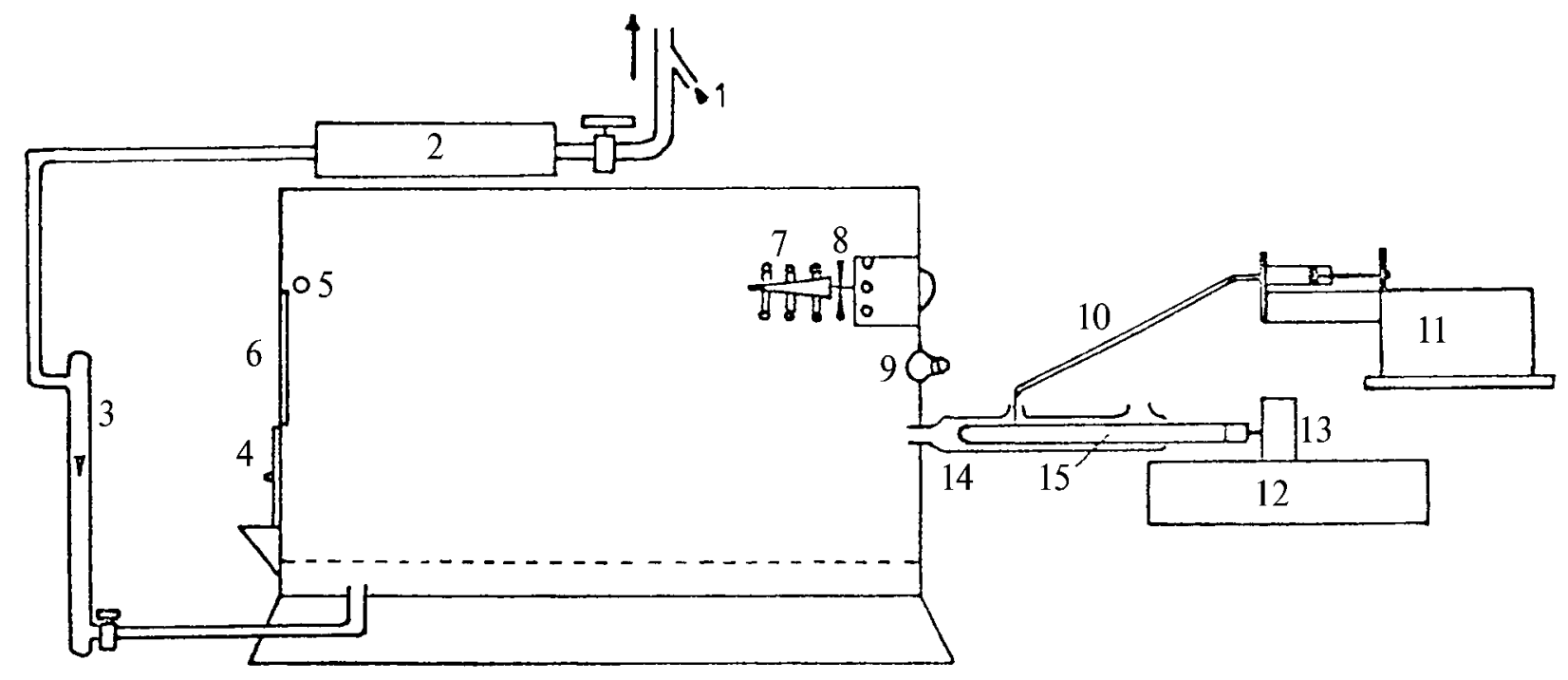

Fig. 1: Scheme of the inhalation instrument.

1 - air suction, 2 - charcoal filter, 3 - flowmeter, 4 - door for inputting animals, 5 - thermometer, 6 - observational window, 7 - cooling (heating) of the air in chamber, 8 - three- bladded propeller, 9 - lighting, 10 - dosing pipette of the syringe, 11 - dosing pump, 12 - instrument for rotating and shifting of the cylinder, 13 - engine with transmission gearing, 14 - glass tubus, 15 - glass cylinder 
The evaporating apparatus consists of a dosing pump and an evaporator. The dosing pump (Braun UNITA 1, B. Braun Apparatebau Melsungen, Germany) applies continuously the OPC from a syringe onto a glass cylinder. The dosing speed as well as the syringe volume are eligible. Syringes of different volumes can be used $(0.5 \mathrm{ml} ; 0.25 \mathrm{ml})$. The evaporator is constructed of the glass cylinder and an instrument for rotating and shifting of the cylinder. This glass cylinder rotates and shifts counter the airflow in order not applying the OPC at the same place. The cylinder is flowed round with air, which is sucking from the hood through 2 openings in a glass tubus. The tubus separates the cylinder from the surroundings and leads the airflow round the cylinder into the chamber. The air temperature is controlled by the temperature sensore located in the front of vapors entry into the chamber. The air is heating at $25^{\circ} \mathrm{C}$. The OPC concentration depends on the following parameters: air-flow, syringe volume, dosing speed.

The inhalation chamber is made of stainless steel and its total volume is 361 . There is a window for observation at each side of the chamber. For air mixing in the chamber the three-bladed propeller is installed. There is a possibility to get light on the inside of the chamber through the lighting fixed at the windows. The animals are input to the chamber through the sealed tipping wicket in steel cages with separated areas for each animal.

\section{Chemicals}

Soman (O-pinacolyl - methyl- phosphonofluoridate) of $80 \%$ purity and sarin (O-isopropyl - methyl- phosphonofluoridate) of $87.5 \%$ purity were obtained from Military Technical Institute in Zemianske Kostolany (Slovak Republic). Their purity was assayd by acidimetric titration. All other chemicals and drugs of analytical grade were obtained commercially and used without further purification.

\section{Determination of soman or sarin concentration}

Samples for determination of soman or sarin concentration in the inhalation chamber were taken as follows: at the side of the chamber there is a special orifice for a glass tube which is connected to the burette $(0.251)$; the burette is for 5 minutes before taking samples evacuated and the sample is taken through opening the tap between burette and the glass tube for $20 \mathrm{~s}$. The glass tube trenchs to the area were the animals breath the air. Than $5 \mathrm{ml}$ of methanol is added to the burette and burette is shaken at the shaker for $15 \mathrm{~min}$. After shaking the eluent is diluted when needed. Soman or sarin concentration is determined by a modification of Ellman method (4). Briefly, to the eluent $(0.2 \mathrm{ml})$ $1.8 \mathrm{ml}$ of butyrylcholinesterase is added, the solution is incubated for $5 \mathrm{~min}$. $1 \mathrm{ml}$ of incubated solution is admeasured into the cuvette and solutions of [5,5'-dithiobis (nitrobenzoic acid)] $(0.5 \mathrm{ml})$ and butyrylthiocholine iodide $(1.0 \mathrm{ml})$ are added. Absorbance changes during $5 \mathrm{~min}$ are monitored using a spectrophotometer (Beckman DU 8, Beckman Instruments Inc., USA) at wavelength of $412 \mathrm{~nm}$.
Soman or sarin concentration in inhalation chamber is calculated according to calibration curve of methanolic solutions of soman or sarin, which were measured using the same modification of Ellman method.

\section{Animals}

Male Wistar rats, weighing 170-220 g, from Konárovice (Czech republic) were kept in air-conditioned room with light from 07:00 to 19:00 $\mathrm{h}$ and were allowed to free access to standard chow and tap water. The rats were divided into five groups of six animals each. Handling of experimental animals was under supervision of the Ethics Committee of the Purkyne Military Medical Academy and the Medical Faculty of Charles university (Hradec Králové, Czech Republic).

\section{Acute toxicity in rats}

The acute toxicity of sarin as well as of soman were expressed as $\mathrm{LCt}_{50}$ with $95 \%$ confidence limits using probit analysis of deaths occuring during $24 \mathrm{~h}$ after inhalation exposure at five different doses with six rats per dose (10).

\section{Statistics}

For yields of OPC means and standard deviations (SD) were calculated.

\section{Results}

The aim of this study was to determine the relationship between nominal and analytical concentration of sarin and soman in the inhalation chamber and to compare the results for these OPC. To prove the utility of the chamber we designated the $\mathrm{LCt}_{50}$ values for sarin and soman in rats.

To determine the relationship between nominal and analytical concentration, we realized 15 measurements for each OPC at different concentrations and the outcomes are shown in Fig. 2 and Fig. 3.

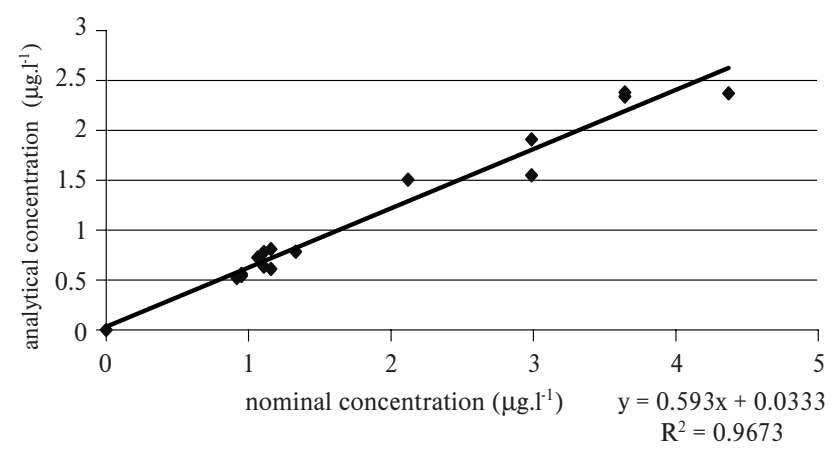

Fig. 2: Concentrations of sarin in the inhalation chamber. Nominal concentration - amount of sarin introduced to the inhalation system relative to the total volume of air flowing through the inhalation chamber. Analytical concentration - the concentration of sarin determined with Ellman method. 


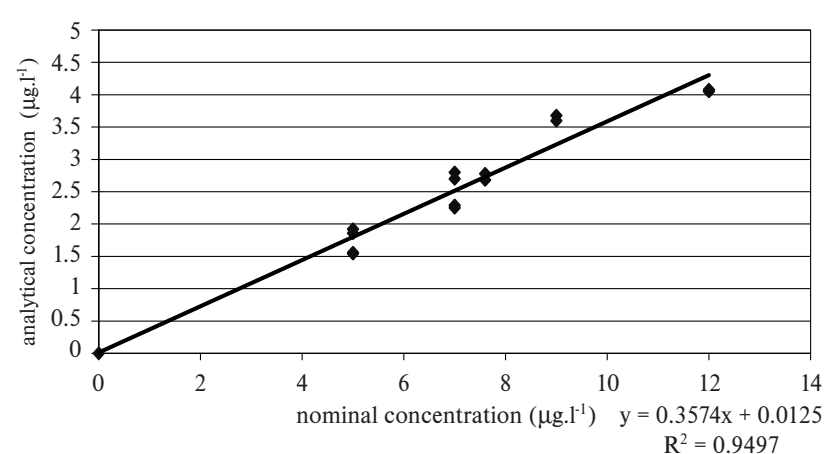

Fig. 3: Concentrations of soman in the inhalation chamber. Nominal concentration - amount of soman introduced to the inhalation system relative to the total volume of air flowing through the inhalation chamber. Analytical concentration - the concentration of soman determined with Ellman method.

The means of the yield were $61.4 \pm 6.6 \%$ for sarin and $35.8 \pm 3.5 \%$ for soman respectively. A stable concentration of tested OPC was obtained after $30 \mathrm{~min}$ of saturation and could be maintained for several hours. The lowest accessible analytical concentration of the OPC in the inhalation chamber was $0.5 \mu \mathrm{g} . \mathrm{l}^{-1}$ because of senstivity of the method used for determination. The highest available analytical concentration of OPC in the inhalation chamber was not studied because laboratory animals are in experiments exposed to sublethal concentrations of OPC vapors (maximum $\left.6 \mu \mathrm{g} \cdot \mathrm{l}^{-1}\right)$.

In order to check the inhalation system with animals inside, we have determined the toxicity of tested OPC in rats. They were exposed to sarin or soman vapors for 1 hour. During $24 \mathrm{~h}$ after exposure occuring of deaths was monitored. The significant difference in $\mathrm{LCt}_{50}$ values for sarin and soman was not observed. $\mathrm{LCt}_{50}$ for sarin was 4.72 mg.h $\mathrm{h}^{-1} \cdot \mathrm{m}^{-3}$ with $95 \%$ confidence limits $4.43-5.04 \mathrm{mg} \cdot \mathrm{h}^{-1} \cdot \mathrm{m}^{-3}$ and for soman $4.81 \mathrm{mg} \cdot \mathrm{h}^{-1} \cdot \mathrm{m}^{-3}$ with $95 \%$ confidence limits 4.57-5.07 mg.h $\mathrm{h}^{-1} \cdot \mathrm{m}^{-3}$.

\section{Discussion}

The results presented show that the inhalation chamber successfully fulfils the role of instrument for inhalation intoxication of small laboratory animals with highly toxic OPC. The stable concentration of the OPC for several hours could be maintained in the inhalation chamber when only relatively small amout of the OPC is consumed. As we anticipated the better yield for sarin than for soman, because of the higher volatility of sarin in comparison with soman (22,000 and 3,900 mg. $\mathrm{m}^{-3}$ respectively), was achieved. Evaporation of the OPC proceeded at a constant temperature $\left(25^{\circ} \mathrm{C}\right)$ maintained by the air heater within all time of the exposure. Then the process of evaporating as well as the OPC concentration in the inhalation chamber depended on the airflow round the cylinder and amount of the OPC applied onto the cylinder. When the air-flow and the OPC amount were constant the OPC concentration in the inhalation chamber was stable.

The optimal number of animals which can be exposed together in the inhalation chamber is 6 for mice and 3 for rats and guinea pigs. The animals are during exposure in metal cages in which they can move, so they are not stressed as much as in nose-only types of inhalation apparatus in which the animals can not move. The possibility of interference of the animal excrements with OPC is in our type of inhalation chamber limited because the place where these excrements are located is near the outlet of the air from the chamber. In nose - only exposure systems the excrements does not cause any problems, because they are separated from the inhaled air. The licking of the fur and extremities increasing the total dose of tested compound is for animals much easier in the whole - body chambers than in nose only systems. This fact handicapes the whole - body inhalation chambers. The $\mathrm{CO}_{2}$ produced by the animals does not influence them during the exposure because the airflow through the chamber is high enough to flush it from the chamber.

This closed dynamic inhalation system does not allow the escape of highly toxic OPC outside the chamber due to the negative pressure inside the instrument. The safety of persons is provided by placing the instrument in the hood.

The values of $\mathrm{LCt}_{50}$ of OPC tested in our inhalation system well correspond with results demonstrated formerly by Schoene et al. using similar model of the inhalation system (16). But it is quite difficult to compare toxicities of these compounds obtained for different times of exposure, because the interaction of $\mathrm{LCt}_{50}$ values increases with exposure duration (12).

In conclusion it was demonstrated that our inhalation chamber enables generating of vapors of toxic OPC in demanded range. The difference in volatility of sarin and soman has been manifested as a different yield in generating of toxic vapors. Because the inhalation route of intoxication is the most probable way of poisoning with OPC, the experiments which mimic these conditions are such important. Further developing of the inhalation instrument in order to monitor all the conditions of exposure (e.g. air humidity, determination of OPC concentration in different parts of the chamber) is the aim of next experiments which will be realized with this type of the inhalation chamber.

\section{Acknowledgement}

The support of the contract Biochemical effect of low level exposure to soman vapour No. A00D448 is gratefully acknowledged. The authors express their appreciation to E. Vodáková for her skill technical assistance.

\section{References}

1. Aas P, Sterri SH, Hjermstad HP et al. A method for generating toxic vapors of soman: toxicity of soman by inhalation in rats. Toxicol Appl Pharmacol 1985;80:437-45. 
2. Anzueto A, de Lemos RA, Seidenfeld $\mathrm{J}$ et al. Acute inhalation toxicity of soman and sarin in baboons. Fundam Appl Toxicol 1990;14:676-87.

3. Benschop HP, Trap HC, Spruit HET et al. Low level nose-only exposure to the nerve agent soman: toxicokinetics of soman stereoisomers and cholinesterase inhibition in atropinized guinea pigs. Toxicol Appl Pharmacol 1998;153: $179-85$

4. Dorato MA, Wolff RK. Inhalation exposure technology, dosimetry, and regulatory issues. Toxicol Pathol 1991;19:373-83.

5. Ellman GL, Courtney DK, Andres V et al. A new and rapid colorimetric determination of acetylcholinesterase activity. Biochem Pharmacol 1961;7:88-95.

6. Henderson RF, Barr EB, Blackwell WB et al. Response of F344 rats to inhalation of subclinical levels of sarin: exploring potential causes of Gulf War illness. Toxicol Ind Health 2001;17:294-7.

7. Henderson RF, Barr EB, Blackwell WB et al. Response of rats to low levels of sarin. Toxicol Appl Pharmacol 2002;184:67-76.

8. Husain K, Vijayaraghavan R, Pant SC et al. Delayed neurotoxic effect of sarin in mice after repeated inhalation exposure. J Appl Toxicol 1993;13:143-5.

9. Kalra R, Singh SP, Razani-Boroujerdi S et al. Subclinical doses of the nerve gas sarin impair $\mathrm{T}$ cell responses through the autonomic nervous system. Toxico Appl Pharmacol 2002;184:82-7.

10. Katedra toxikologie, Vojenská lékařská akademie. LD50 [software online]. 2003, last revision 27.2.2003 [cit. 2003 - 05 - 06]. Available from: http://www.toxi.pmfhk.cz.

11. Langenberg JP, Spruit HET, van der Wiel HJ et al. Inhalation toxicokinetics of soman stereoisomers in the atropinized guinea pig with nose - only exposure to soman vapor. Toxicol Appl Pharmacol 1998;151:79-87
12. Mioduszewski R, Manthei J, Way R et al. Interaction of exposure concentration and duration in determing acute toxic effects of sarin vapor in rats. Toxicol Sci 2002;66:176-84

13. OECD guideline for the testing of chemicals. Acute inhalation toxicity. OECD 1996.

14. Pauluhn J. Overview of testing methods used in inhalation toxicity: from facts to artifacts. Toxicol Lett 2003;140-1:183-93.

15. Phalen RF, Mannix RC, Drew RT. Inhalation exposure methodology. Environ Healt Perspect 1984;56:23-34.

16. Schoene K, Hochrainer D, Oldiges $\mathrm{H}$ et al. The protective effect of oxime pretreatment upon the inhalative toxicity of sarin and soman in rats. Fundam App Toxicol 1985;5:S84-8.

Submitted July 2003.

Accepted August 2003.

Mgr. Lucie Ševelová,

P.O. Box 35/T,

Purkyně Military Medical Academy,

50001 Hradec Králové,

Czech Republic.

e-mail: sevelova@pmfhk.cz 